\author{
(DEPAR'TAMFNT() DE RADIODIAGNÓSTICO E FISIOTHKAPIA \\ Diretor: Prof. Honorato F. Oliveira Jr \\ O DUPLO CONTRASTE NAS RADIOGRAFIAS DE \\ COLO NOS CĀES \\ DOUBIE CONTRAST IN DOG'S COLON X RAY \\ HONORATO F. OLIVEIRA JR
}

A visualização do colo com duplo contraste por via retal para completar sua exploraçāo, pondo em relêvo lesōes da mucosa, foi obtida pela primeira vez, em 1896, por BECHER (in AHERN-1954) que usou como enema uma soluçāo de acetato de chumbo, insuflando ar em seguida. Em 1923 roi utilizado por FISCHER (in AHERN ) o duplo contraste com enema de sulfato de bário, conseguindo imagens de escasso contraste. MORETON (in AHERN) e seus colaboradores descobriram em 1951 que a causa das imagens serem pouco satisfatórias era o endurecimento do bário sôbre as paredes intestinais. A correçāo foi feita em 1954 por AHERN que, injetando ar imediatamente após o enema de bário ( 11 partes de hário para 18 de água, agitada a mistura durante 20 minutos), aperfeiçou a imagem obtida com duplo contraste.

O método de AHERN com algumas modificações, é o que propomos se vulgarize em radiologia veterinária.

\title{
OBSERVAC̄OES PESSOAIS
}

Utilizando para o enema, mistura de sulfato de bário e água agitada em alguns casos durante 20 minutos e em outros apenas 8 , fizemos experimentos em 12 cães, sendo 2 previamente narcotizados, de acôrdo com o esquema seguinte:

$\begin{array}{cccc}\text { N. }{ }^{\circ} \text { de cães } & \begin{array}{c}\text { Percentagem } \\ \text { da mistura }\end{array} & \begin{array}{c}\text { Tempo de } \\ \text { agitação }\end{array} & \begin{array}{c}\text { N. }{ }^{\circ} \text { de } \\ \text { radiografias }\end{array} \\ 1 & 10^{\prime} & 20 & 4 \\ 2 & 20 & 20 & 4 \\ 4 & 30 & 20 & 16 \\ 2 & 30 & 8 & 4 \\ 1 & 50 & 20 & 2 \\ \text { Narcotizados } & & & \\ 1 & 30 & 20 & 4 \\ 1 & 30 & 8 & 4\end{array}$


Os animais foram privados da refeição da tarde e, de manhã. após submetidos a enema liquido, colocados na mesa com inclinacão de 20 graus em direção cefálica.

Conforme o tamanho do animal usamos 50 a 100 c.c. de enema de bário e, sem visualização radioscópica, insuflamos imediatamente ar. O contrôle da insuflação foi obtido pela pera de Richardson, mantida com a máxima quantidade de ar durante a radiografia. Todas as operaçōes foram feitas com rapidez para evitar o endurecimento do bário no cólo antes de terminados os procedimentos de replexão e radiográficos.

As radiografias revelaram melhor contraste quando utilizada a mistura de bário na proporçāo de $30 \%$ e agitada durante 20 minutos até o momento do enema.

A narcose dos cāes facilitava todas as operações mas dificultava c. retenção do ar insuflado.

Os animais foram radiografados em decubito com incidência ventro dorsal (fig. 1-2), dorso ventral ( fig. 3-4-5), decubito lateral com incidència esquerda (fig. 6), e lateral com incidéncia direita (fis. 7 ).

Nas radiografias, extraordinariamente nitidas, com Bucky, $35 \mathrm{~K}$. v., 20 M. S., $75 \mathrm{~cm}$. de distância, o colo, em sua primeira porção, curta, à direita (colo ascendente), dirige-se para diante, ¿té a regiāo gástrica; ai se curva para à esquerda e forma ao atravessar o plano médio, a porção transversal (colo transverso) com disposição variável em ângulo ou curvatura ; ao dirigir-se para traz pela regiāo sub lombar, constitue o terceiro ramo i esquerda ( co!o descendente), que se inclina depois para o plano médio e continua com o reto.

\section{SUMMARY}

Clear radiographic visualization of the colon of the dog by double contrast was obtained after rectal administration of a 30 per cent prepared barium water suspension.

\section{BIBLIOGRAFIA}

AHERN, E C. - 1954 - Estudio del colon con doble contraste. Radiogr y. Fotogr Clin., 20 (3): 73-75 


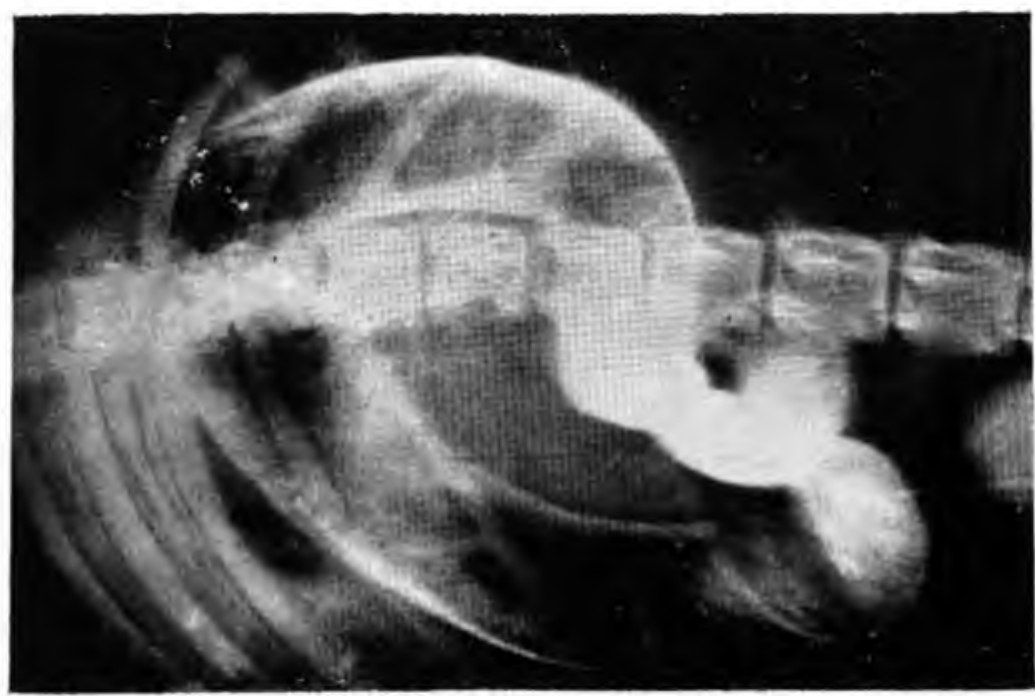

FIG. 1

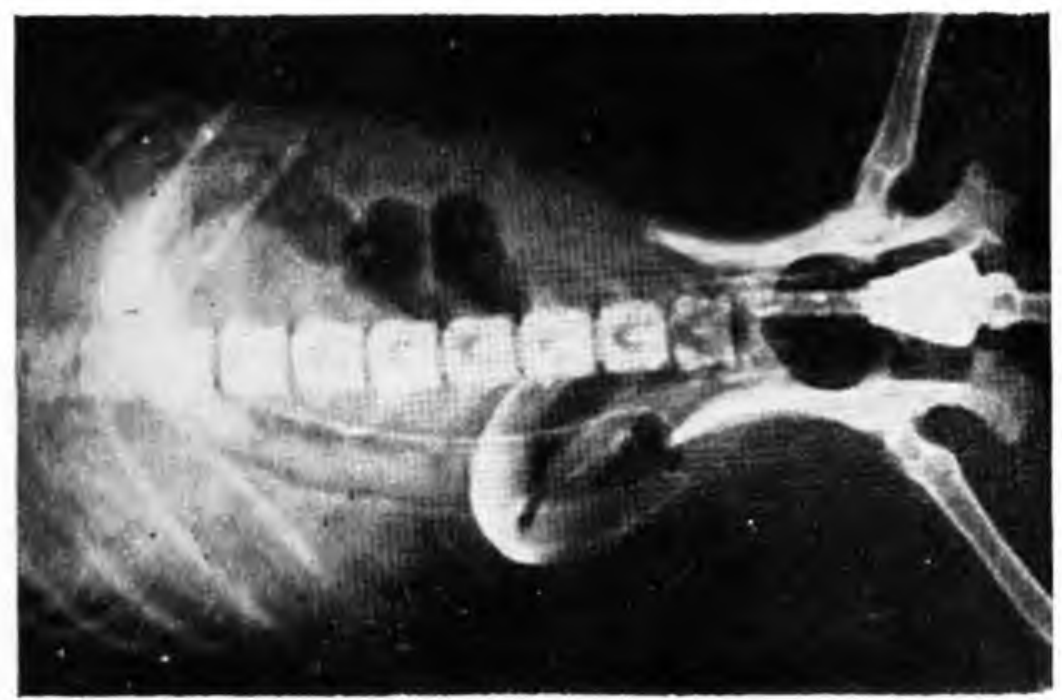

FIG. 2 


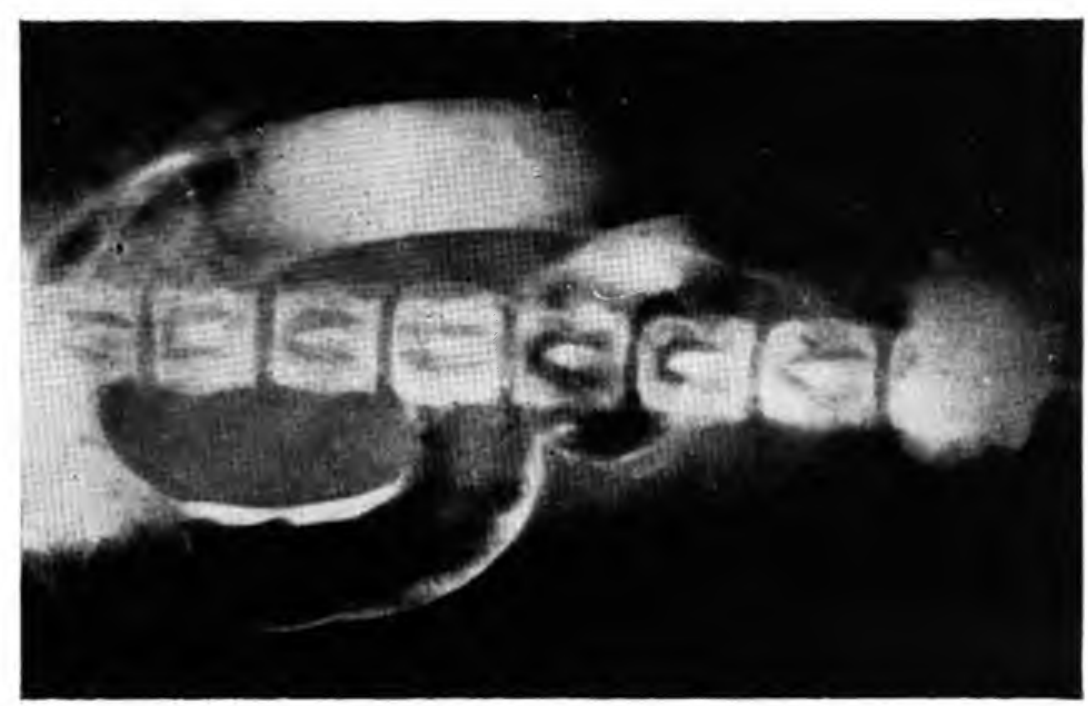

FIG. 3

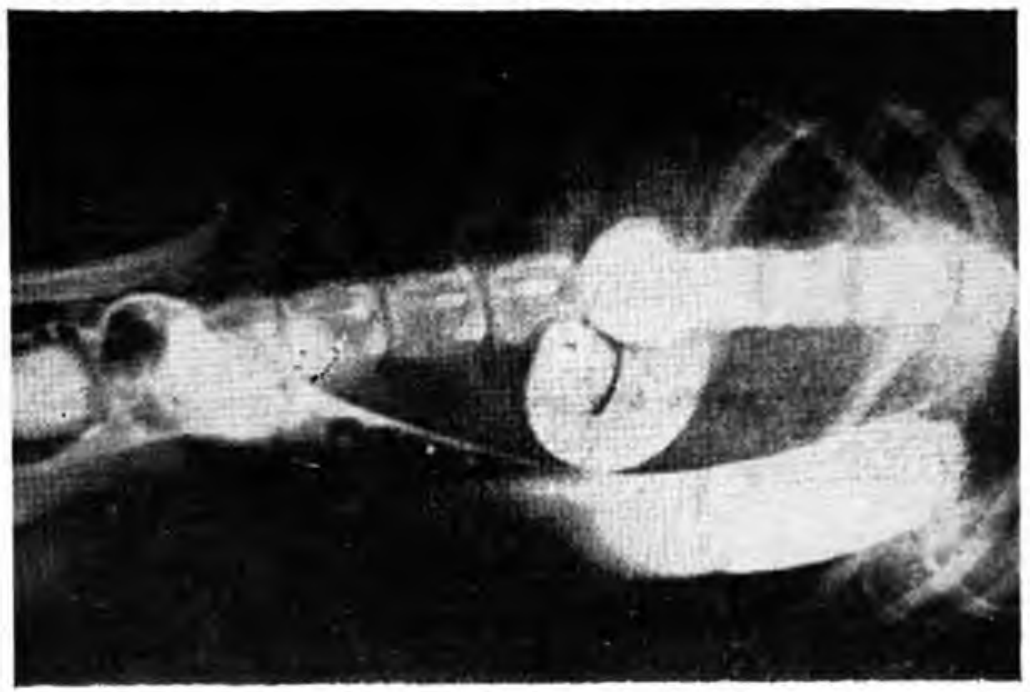

FIG. 4 


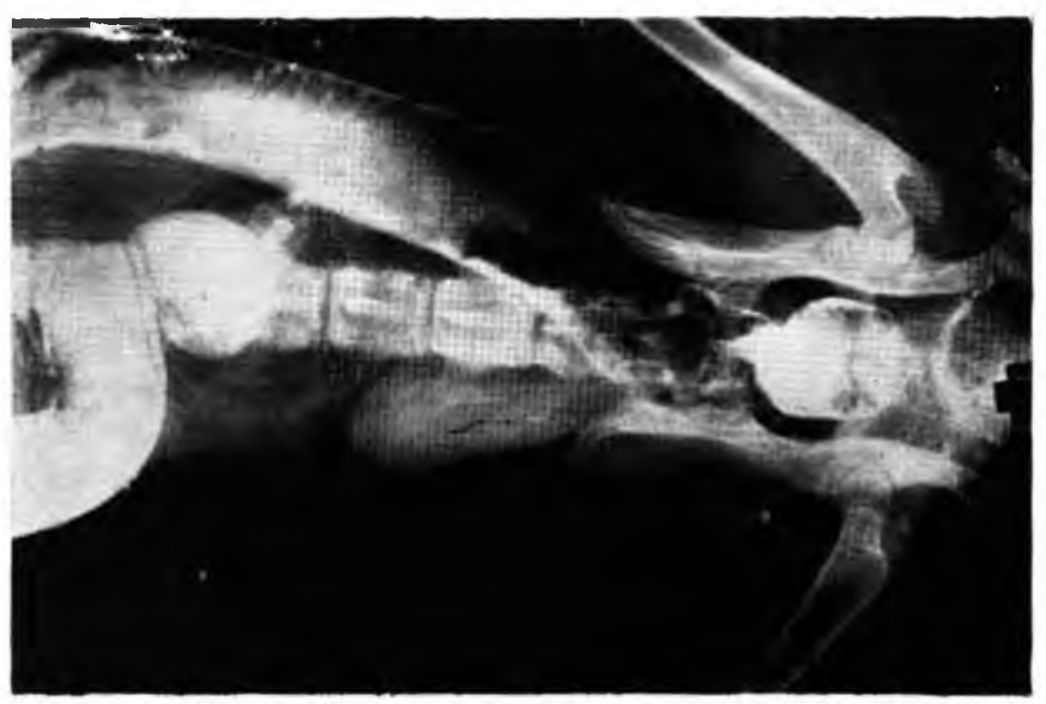

FIG. 5

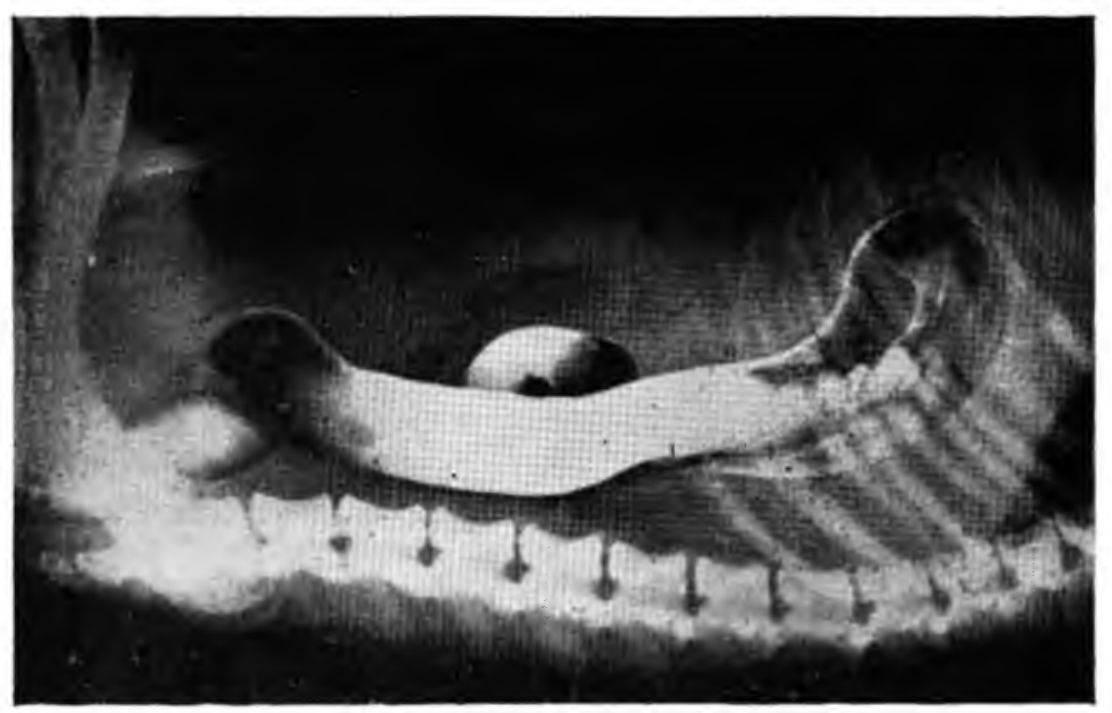

FIG. 6 


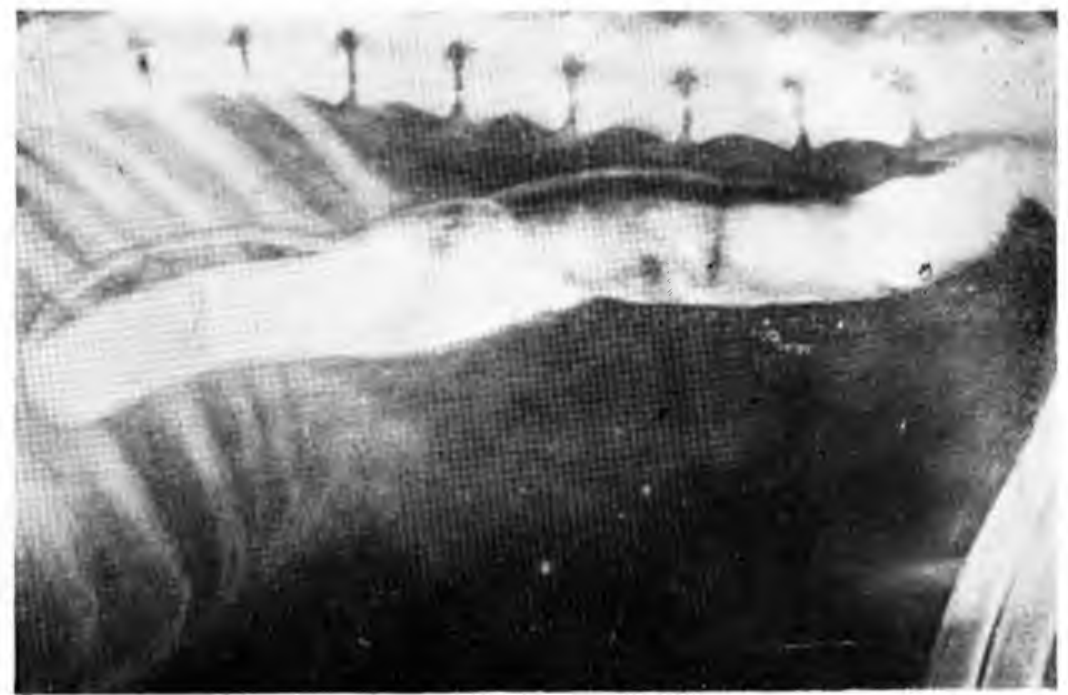

FIG. 7 